\title{
DAS CRÍTICAS ÀS POSSIBILIDADES: \\ PERSPECTIVAS DE ATUAÇÃO DA EDUCAÇÃO FÍSICA EM SAÚDE COLETIVA'
}

\author{
GRAD. MICHEL BINDA BECCALLI \\ Graduado em Educação Física pela ESFA/ES e Mestrando do Programa de \\ Pós-Graduação em Educação Física da Universidade Federal do \\ Espírito Santo (UFES), Membro do LESEF/CEFD/UFES \\ (Vitória - Espírito Santo - Brasil) \\ E-mail: michelbeccalli@hotmail.com

\section{DR. IVAN MARCELO GOMES}

Doutor em Ciências Humanas pela Universidade Federal de Santa Catarina (UFSC)

Professor do Programa de Pós-Graduação em Educação Física da UFES

Pesquisador do LESEF/CEFD/NFES e do Núcleo de Estudos e Pesquisas Educação e Sociedade

Contemporânea da UFSC

(Vitória - Espírito Santo - Brasil)

E-mail: ivanmgomes@hotmail.com

I. Houve financiamento da CAPES, na modalidade de bolsa de mestrado, para a realização deste trabalho. 
A temática da atuação do profissional de Educação Física no âmbito da Saúde Coletiva tem sido explorada de maneira crescente no âmbito acadêmico, apontando para a necessidade de se (re)pensar a formação profissional voltada para esse fim. Nessa perspectiva, foi lançado o livro Educação Física e Saúde Coletiva: políticas de formação e perspectivas de intervenção, que busca evidenciar questões que abrangem desde a formação inicial de profissionais para atuarem nessa área até o fomento de reflexões acerca da sustentabilidade do paradigma que se estabelece como hegemônico no âmbito da Saúde Coletiva; a obra pretende, além disso, incitar novos olhares do/sobre o campo da Educação Física, fortalecendo suas (inter)faces com a Saúde Coletiva. Para dar suporte a tais problematizações, autores de formações diversas dentro do âmbito da Saúde compõem a obra, sendo a grande maioria do campo da Educação Física.

O livro, organizado por Alex Branco Fraga e Felipe Wachs, é composto por nove textos e apresenta, ao final, um documento intitulado "Carta de Porto Alegre", cuja composição se deu a partir da conjugação de recomendações do relatório final do "Seminário de Educação Física e Saúde Coletiva: a inserção no SUS", realizado no ano de 2006, na capital gaúcha. Os textos transitam entre reflexões sobre a temática e experiências realizadas no âmbito da formação e atuação profissional da área.

Em seu primeiro texto, denominado "Educação Física e saúde coletiva: papel estratégico da área e possibilidades quanto ao ensino na graduação e integração na rede de serviços públicos de saúde", a cientista social Madel Therezinha Luz aborda a crescente inserção do profissional de Educação Física no âmbito da Saúde Coletiva, apontando para uma formação inicial deficitária para esse tipo de atuação, no sentido de que falta ao profissional de Educação Física um olhar descentralizado do indivíduo singular e voltado para uma coletividade. Nesse sentido, a autora problematiza o que considera a falta de uma "consciência sanitária", a qual consiste, além da visão de coletividade, num olhar que privilegie o ser humano enquanto unidade.

A seguir, Vera Maria da Rocha, professora de Educação Física e fisioterapeuta, e Carla Haas Centurião, fisioterapeuta, no texto intitulado "Profissionais da saúde: formação, competência e responsabilidade social", argumentam que, tradicionalmente, as intervenções em saúde são focadas na patologia, apontando para a necessidade de descentralização do modelo médico hegemônico, sem, com isso, fragmentar a assistência prestada pelos serviços de saúde. Cabe ressaltar, conforme apontam as autoras, que a formação profissional se dá a partir de um recorte de alguns componentes da dimensão saúde/doença, recorte esse que gera um isolamento da doença (retirada de seu contexto). Nesse sentido, são apontados limites ao conhecimento advindo do âmbito científico, sendo apresentada como possibilidade uma integração entre conhecimento científico e os demais saberes 
construídos a partir do cotidiano, especialmente do senso comum. A partir de tal perspectiva, torna-se fundamental a desconstrução da hierarquia estabelecida entre profissional de saúde e usuário, estabelecendo um vínculo mais próximo entre ambos. Para dar suporte a esse tipo de ação, é fundamental uma formação embasada em competências - de maneira geral, "capacidade para o desenvolvimento de ações de promoção, prevenção, proteção e reabilitação da saúde, em níveis individual e coletivo, assegurando uma prática integrada e contínua com as demais instâncias do sistema de saúde" (ROCHA, CENTURIÃO, 2007, p. 27) - que envolvem a articulação entre conhecimento, habilidades e contextualização. Para tal fim, seria necessária a reestruturação dos papéis do professor e do estudante, bem como do espaço institucional de ensino e trabalho.

No texto "A formação profissional em Educação Física enseja perspectivas (críticas) para a atuação na saúde coletiva?", Marcos Bagrichevsky, professor de Educação Física, alerta sobre as limitações de se assumir um discurso que tenha o exercício físico enquanto elemento fundante da área. Há uma crítica fortemente marcada à compreensão da saúde enquanto fenômeno medicalizado, apresentando alternativas a tal modelo, a partir do exemplo de uma reorientação do direcionamento político-pedagógico de um curso de Educação Física, implantado em Blumenau (SC), no ano de 2005.

No quarto texto denominado "Singularidade da Educação Física na saúde: desafios à educação de seus profissionais e ao matriciamento interprofissional", o sanitarista Ricardo Burg Ceccim e Luiz Fernando Bilibio iniciam a problematização da temática a partir de questões relacionadas à educação corporal, demonstrando o forte enquadramento da Educação Física nos moldes do paradigma biomédico para se inserir na Saúde Coletiva. A partir de tal constatação, os autores trazem reflexões sobre a necessidade de se (re)pensar essa aproximação, no sentido de que a Educação Física deve trazer uma nova perspectiva a Saúde Coletiva ao invés de perspectivar-se a partir desta. A problematização segue com a exploração da dimensão emblemática que o corpo assume na atualidade, sendo marcado pelas escolhas realizadas em que o vigor corporal, interpretado como sinônimo de saúde, bem como o ato de movimentar-se, adquire conotação de promoção/produção de saúde. A partir de tal problematização, os autores questionam o dogma "atividade física é saúde", direcionando a discussão para a necessidade de uma compreensão mais ampliada do ser humano, visto que o indivíduo mobiliza "junto com um corpo de ossos e músculos, um corpo de afetos e de expansão da experiência humana" (CECCIM; BILIBIO, 2007, p. 54), possibilitando à Educação Física a reordenação da dimensão corpórea da existência subjetiva na prática cuidadora. 
No texto "Práticas corporais e comunidade: um projeto de Educação Física no Centro de Saúde Escola Samuel B. Pessoa (Universidade de São Paulo)", a professora Yara Maria de Carvalho demonstra um exemplo de intervenção pautada em cinco princípios básicos: cuidado; transversalidade; práticas corporais como componentes da cultura corporal; integralidade; e autonomia. A autora alerta para a necessidade de desnaturalização de comportamentos, pensamentos e práticas, atentando para a historicidade desses, reforçando, por exemplo, que até mesmo necessidades são criadas e introjetadas.

Em "Das possibilidades às incertezas: instrumentos para intervenção do profissional de Educação Física no posto de saúde”, José Geraldo Soares Damico, professor de Educação Física, demonstra a fragilidade de manutenção de um olhar descontextualizado sobre o usuário ao apontar para o espaço de atuação do profissional de Educação Física e para a orientação à prática de atividade física de maneira sistemática e assistida, citando, a partir de sua experiência profissional, a importância de se levar em consideração as dimensões social e afetiva na intervenção cotidiana, provocando inquietações no que diz respeito ao papel do profissional no âmbito da Saúde Coletiva e incitando reflexões acerca do processo de naturalização de determinadas condutas/posturas.

Felipe Wachs, professor de Educação Física, problematiza a intervenção do profissional de Educação Física no âmbito da saúde mental em "Educação Física e o campo da saúde mental: uma reflexão introdutória”, evidenciando o processo de institucionalização da loucura, questionando o utilitarismo da atividade física ao contribuir com a docilização dos corpos, estando, nesse sentido, a Educação Física submissa ao saber médico. $O$ autor segue sua argumentação destacando esses e outros aspectos a partir de sua experiência no Programa de Residência Integrada com ênfase em Saúde Mental Coletiva da Escola de Saúde Pública do Rio Grande do Sul.

No texto "A Educação Física bate à porta: o Programa de Saúde da Família (PSF) e o acesso à saúde coletiva", Dagoberto de Oliveira Machado, professor de Educação Física, ao utilizar metaforicamente a figura da porta para refletir sobre a articulação entre Educação Física e Saúde Coletiva, inicia com o apontamento do PSF como espaço para atuação do profissional de Educação Física, seguindo com considerações acerca da formação inicial e a necessidade de atrelar a essa atuação os princípios do Sistema Único de Saúde, enfatizando a possibilidade da Educação Física enquanto "porta" da saúde coletiva. Ao finalizar, o autor indica ser fundamental a abertura para novas possibilidades para que "novas portas se abram".

Finalizando o livro, os professores de Educação Física Alex Branco Fraga, Igor Ghelman Sordi Zibenberg, Rute Viégas Nunes, Felipe Wachs e Dagoberto de Oliveira Machado apresentam, em "Significados de atividade física e saúde em 
caminhantes: das camadas metodológicas à construção de uma agenda analítica", o percurso metodológico de uma investigação realizada em Porto Alegre, dividida em três camadas. A primeira diz respeito à escolha do lócus de pesquisa; a segunda está relacionada à seleção de sujeitos; e a terceira se refere à construção do instrumento. A ênfase dada ao percurso da construção é justificada pelas peculiaridades desta, bem como o valor atribuído à construção em detrimento dos resultados em si. Os autores finalizam o texto com uma breve explanação sobre a compreensão dos caminhantes sobre atividade física e saúde.

Enquanto unidade, o livro possui caráter introdutório às discussões que tangenciam a Educação Física em sua(s) interface(s) com a Saúde Coletiva, devido à multiplicidade de aspectos abordados, permitindo, portanto, que se tenha um panorama acerca da inserção da Educação Física no âmbito da Saúde Coletiva. São desenvolvidas considerações fundamentais para o campo, permeando desde o olhar da primeira sobre a segunda até o olhar desta em relação à primeira. $\bigcirc$ livro abrange questões relacionadas ao âmbito da formação, bem como da atuação, dando visibilidade a limites e possibilidades de ações que têm sido desenvolvidas. A obra contém argumentos coesos e, embora demonstre olhares diversos sobre a Educação Física, as perspectivas se aproximam.

Entretanto, ao tratar do olhar da Saúde Coletiva em relação à Educação Física, percebe-se que este se constitui/constrói de maneira relativamente superficial, pois infere uma homogeneidade ao campo que, de fato, não existe, apontando para a necessidade de uma "consciência sanitária", incluindo nas práticas corporais categorias que não se esgotam no "físico". A Educação Física vem se debruçando sobre esse tipo de questão há algum tempo, ainda que não haja consenso a esse respeito. Nesse sentido, talvez não seja possível afirmar que esse tipo de reflexão é ausente, embora seja necessário admitir que é, ainda, muito pouco expressiva no campo e com alcance limitado. Por outro lado, talvez essa visão se deva a uma relativa timidez da Educação Física no âmbito da Saúde Coletiva e, ainda, a uma fragilidade argumentativa por restringir esse tipo de discussão ao âmbito da própria Educação Física, limitando, portanto, o diálogo com outras áreas de conhecimento.

Muitos dos textos buscam evidenciar as questões apontadas por intermédio de um resgate histórico da constituição da Educação Física, com ênfase na influência higienista por ela sofrida, problematizando sua aproximação com a Saúde Coletiva a partir do tangenciamento ao discurso/paradigma biomédico, o qual é hegemônico nessa área, demonstrando que se, por um lado, essa aproximação proporciona inserção associada à relativa aceitação/legitimaçãa de sua atuação, por outro, priva a Educação Física de poder proporcionar uma maneira diferente de ver/compreender o campo da Saúde Coletiva e o cuidado em saúde. 
Nesse contexto, não se pode esquecer que, a partir de modelos de cuidado hospitalocêntricos e com foco na patologia, o sujeito se perdeu como unidade, sendo necessário, portanto, romper com tal visão fragmentada do humano e, por que não dizer, da vida. Enfatizando esse apelo por um olhar integrado e integrador, a prática interdisciplinar é constantemente apontada como necessidade. $\bigcirc$ caráter interdisciplinar se mostra presente, em alguns momentos, tratando da necessidade de diluir relações de poder estáticas, convertendo-as em uma via de mão dupla, tanto no que se refere às relações estabelecidas entre profissionais que atuam no âmbito da Saúde Coletiva, quanto em relação a profissionais e usuários.

Embora em diversos momentos haja uma argumentação bastante incisiva em relação ao paradigma hegemônico presente no fazer científico, especialmente nesse âmbito, no sentido de evidenciar suas limitações, parece ser consenso entre os autores que a tentativa de transcender esse modelo não implica negá-lo, bem como não implica refutar todos os avanços obtidos por intermédio deste.

Nota-se na Educação Física a herança e produção de uma educação do corpo que foi fortemente marcada/pautada pelo paradigma biomédico. Dada a limitação do conceito de atividade física para designar a compreensão trazida pelos autores, a qual busca desconstruir o enfoque biologicista de tais práticas, o termo "práticas corporais" recebe destaque. Embora não seja suficiente apenas a substituição de uma nomenclatura para superar essa lógica, reconhecemos que uma nova designação opera com outro universo simbólico, trazendo novas possibilidades instituintes que procuram se desvencilhar da carga semântica tão atrelada ao enfoque questionado.

É possível, ainda, refletir sobre os traços ainda existentes da visão higienista, levando ao questionamento: até que ponto a intervenção em saúde, pensada a partir de um foco hospitalocêntrico, marcado pela superespecialização, é capaz de se encarregar da compreensão do universo de complexidade que constitui o ser humano?

Certamente, diversas críticas são feitas nesse sentido e têm sido cada vez mais expressivo no campo da Educação Física um discurso que sustenta a formação de indivíduos que superem tal visão fragmentada, e, em argumentos dos mais variados matizes, se espalha a importância da formaç̧ão crítica na condução de estilos de vida. Contudo, é necessário questionar: que criticidade é essa? Tem sido cada vez mais perceptível o crescimento do discurso que defende o estilo de vida ativo, que tem sido cada vez mais atrelado a uma visão correta (moral e racional) sobre a vida. Ou seja, só é crítico, de fato, o indivíduo que "faz a escolha certa" e opta por uma vida ativa. A partir dos questionamentos lançados e as reflexões provocadas pela leitura da obra, é possível questionar em que medida essa perspectiva se sustenta. Por outro lado, é necessário destacar que até mesmo a vertente crítica 
da epidemiologia, da qual a obra é expressão e veículo, pode incidir na mesma armadilha ao postular uma forma de "dever ser" do indivíduo crítico e autônomo frente ao discurso da vida ativa.

Outro ponto fundamental que aparece de maneira expressiva é a aproximação/distanciamento da Educação Física com o paradigma biomédico. Os autores direcionam a discussão para as potencialidades do campo, contribuindo com uma visão complementar - no sentido de ser diferente e não-subordinada a esse paradigma - sobre o processo saúde/doença. Assim, a Educação Física deve contribuir com a Saúde Coletiva através de outra perspectiva, em vez de perspectivar-se a partir desta. Algumas possibilidades, nesse sentido, são apontadas, dando-se grande destaque à formação inicial como fundamental no processo de rompimento com esses vínculos engessados/cristalizados que se tornaram - em alguma medida, e por determinado período - dogmas. Há, então, uma aposta na efetiva incorporação do princípio da integralidade desde a formação inicial até a continuada, atentando para uma maior proximidade com o ato cuidador. Há, inclusive, apontamento para relativa carência de proximidade do campo com a prática cuidadora, sendo necessária a compreensão de que um corpo de ossos e músculos não está desvinculado de um corpo de afetos.

É possível perceber que a Educação Física pode contribuir no âmbito da saúde pública, no sentido de auxiliar na expansão da visão acerca do ser humano, sendo imprescindível o estabelecimento de uma relação interdisciplinar. Entretanto, se atentarmos para a hiperespecialização e o isolamento de áreas e subáreas, um longo e conflituoso caminho ainda está por ser construído. Tal ponderação não exige resignação e o livro em questão é prova disso.

Diversas são as críticas feitas pelos autores e diversos são os caminhos apontados. Embora não seja possível visualizar um "caminho seguro" a ser trilhado, é louvável a iniciativa da obra por, dentre diversas razões, fazer emergir uma leitura mais minuciosa de questões que envolvem esses campos, bem como a revisão e reflexão sobre axiomas e dogmas naturalizados e pressupostos cristalizados/engessados. Mesmo que a obra não represente um marco inicial desse tipo de discussão, podemos reconhecer - e, certamente, é necessário destacar - que se constitui como um avanço significativo no debate acerca da temática.

\section{REFERÊNCIA}

FRAGA, A. B.; WACHS, F. (Org.). Educação fsica e saúde coletiva: políticas de formação e perspectivas de intervenção. Porto Alegre: Ed. da UFRGS, 2007. 
Recebido: | mar. 201 | Aprovado: 3 jun. 2011

Endereço para correspondência Michel Binda Beccalli Universidade Federal do Espírito Santo Centro de Educação Física e Desportos Laboratório de Estudos em Educação Física Av. Fernando Ferrari, 5/4 Campus Universitário Goiabeiras Vitória - ES CEP: 29075-8I0 